\title{
Transient Antiseepage Analysis of the Relief Well in Beijiang Dike
}

\author{
Wenbing Xu, ${ }^{1}$ Chuan $X u^{2}{ }^{2}$ Qinghe Yao $\unrhd^{1},{ }^{1}$ Trevor Hocksun Kwan, ${ }^{1}$ and Sheng Wang ${ }^{1}$ \\ ${ }^{1}$ Department of Applied Mechanics and Engineering, Sun Yat-Sen University, Guangzhou, Guangdong, China \\ ${ }^{2}$ Taishan Nuclear Power Joint Venture Co., Ltd., Guangzhou, Guangdong, China \\ Correspondence should be addressed to Qinghe Yao; yaoqhe@mail.sysu.edu.cn
}

Received 23 April 2020; Accepted 20 May 2020; Published 20 July 2020

Guest Editor: Rongwei Guo

Copyright $\odot 2020$ Wenbing Xu et al. This is an open access article distributed under the Creative Commons Attribution License, which permits unrestricted use, distribution, and reproduction in any medium, provided the original work is properly cited.

In this paper, the seepage finite element method (FEM) is used to simulate the transient seepage of Beijiang Dike, and antiseepage solutions are designed and discussed. By comparing the measured data of a piezometer with the steady-state calculation model, the calculated results are compatible very well with the measured data. Aiming to improve the ability to respond in extreme weather conditions, we calculate the transient seepage field after the water level suddenly rises in a short time and then select the relief well as the antiseepage measure and optimize it. The results show that when the water level is $15.78 \mathrm{~m}$, the slope reaches 0.5 , and the embankment is damaged. With the increase of penetration depth, the effect of drainage and decompression in the depth of $3 / 5$ and $4 / 5$ is relatively small due to geological strips. Due to different geological conditions, the same relief wells are placed in different positions with a wide gap in effect, the antiseepage effect is the best when the horizontal distance is $95 \mathrm{~m}$, and the effect is the best when the depth is $16.5 \mathrm{~m}$. The research results can be used to guide the seepage prevention and control design of Beijiang Dike.

\section{Introduction}

Embankment engineering is the foundation of the flood control engineering system and an important barrier against flood [1]. For a long time, China's embankment project lacks sufficient attention and research; there are still many problems such as unstable quality of levee body, poor impervious capability, and lack of effective monitoring measures. Among all safety problems, seepage failures are the most critical and common problem in levee engineering $[2,3]$. In 1998, an extreme flood occurred in the Yangtze River, and the seepage danger in the middle and lower reaches of the Yangtze River reached 65,100, accounting for $88 \%$ of the total risk. Among the seven large crevasses, 5 of them were due to the penetration deformation and the osmotic failure, which eventually led to the collapse of the embankment [4]. Since then, researchers have paid more attention to the safety of dike engineering, and seepage analysis of dike engineering has become one of the current research hotspots [5-8].

Seepage analysis is a study of fluid mechanics, geotechnical mechanics, and other interdisciplinary fields. In 1856, French scholar Henry Darcy used a vertical circular pipe to conduct sand seepage experiment, which was the first seepage analysis method. Then, he proposed Darcy's law [9]. In 1889, people first deduced the seepage differential equation. After that, the analytical method of seepage analysis has been applied by a large number of researchers, and a series of fruitful results have been achieved, which promotes the development of seepage-related research rapidly. However, the analytical method is difficult in practical application because it has the defects of large amount of calculation and general adaptability in dealing with more complex problems, so it is relatively difficult to apply in practical engineering. In 1922, Pavlovski developed an electrical simulation method for seepage analysis due to the difficulty of seepage in nonuniform permeable medium and complex boundary. In 1931, Richards established Richards equation for unsaturated seepage analysis by further derivation of mass conservation law and generalized Darcy law [10]. Then, Fredlund and Lam [11] put forward the saturated-unsaturated seepage control equation in the following research, which brought a qualitative leap to the engineering construction.

The seepage analysis method of dike engineering mainly includes model experiment, numerical simulation, and data 
analysis [12-14]. Model experiments often require a large amount of workforce and material resources; therefore, they are expensive. Due to the limitation of experimental conditions, it is difficult to conduct comprehensive research of various special working conditions. Data analysis requires an on-site survey and collection of a large number of monitoring data, which often requires high economic costs. The numerical simulation has lower cost and higher precision and can simulate a variety of working conditions, and the appropriate conditions can be obtained to obtain higher precision results. Therefore, relevant research is currently conducted using numerical simulation.

Many scholars use the finite element analysis (FEA) method to simulate seepage in dike engineering. Moran [15] first applied the finite element method to analyze the steady flow of incompressible fluid in saturated porous media and put forward the view that the finite element method is applicable to all field problems calculated by the variational formula. However, he did not optimize the antiseepage scheme. Zhang [16] conducted typical conditions for the present situation of an embankment project in the middle and lower reaches of the Yangtze River. The seepage field of dike foundation was simulated and calculated by a finite element numerical simulation method. The effects of the thickness of the strong permeable layer hidden in the ground and exposed to the surface, the width of the dyke, and the degree of cutting of the channel on the levee were also studied. However, there is lack of analysis of the critical conditions when the dam is damaged. Vermeer et al. $[17,18]$ use a first-order reliability method of adaptive response surface coupled with numerical simulation and reliability analysis to analyze transient seepage. Considering the influence of transient seepage in an embankment on stability, analysis of stable phreatic line is the key to the stability control. Although a new seepage analysis method is adopted, the analysis of seepage slope and other factors is lacking. Wu et al. [19] used the finite element program COMSOL to solve the influence of rainfall seepage, deformation, and stability of soil slope. Through the finite element analysis software GeoStudio, Qiu et al. [20] carried out numerical analysis of seepage stability of the stable flow of embankment engineering combined with engineering examples, focusing on the comparison and evaluation of seepage characteristics before and after pile foundation construction. Although the above two people used different software to make a detailed analysis of the seepage of the slopes and embankments, there was lack of antiseepage schemes.

In the simulation study of the antiseepage effect of the relief well, Zhang[21] analyzed the effectiveness of various antiseepage measures of Beijiang Dike through the analysis of measured data and the simulation calculation of steady seepage field. He believed that the seepage control and decompression project was sufficient for the dike section. He also evaluated the seepage control safety of the dike, which provided a reference for the construction of the dike. Based on steady-state seepage, $\mathrm{Li}$ [22] calculated the penetration depth, diameter of the well casing, well spacing, the elevation of water outlet, and permeability of the filter layer in the twodimensional seepage finite element method. Based on the geological data of the Beijiang Dike, the model of the Shijiao segment section of the Beijiang Dike is established. On this basis, the transient seepage field of the relief well is optimized and the seepage flow is reduced under extreme conditions in the actual dike project. Protecting the safety of dikes is of great significance.

Located in the lower reaches of the Beijiang River, Beijiang Dike is an important barrier for the defence of the Xijiang and Beijiang floods in Guangzhou and is also a national first-class dike. The total population of the dike area is more than 5 million, and the cultivated land is 44.66 million square meters. It is one of the seven significant embankments in China. However, there are few safety analyses for it, especially in extreme weather. Therefore, this paper will adopt seepage finite element software to simulate the seepage field of Beijiang embankment instantaneously and verify it by comparing with the measured value of the pressure pipe.

As mentioned in the literature above, most of the current simulation analysis of relief wells is based on steady seepage field, which lacks the support for analysis of transient behaviour. Few studies have been carried out to calculate the change of seepage control effect of relief wells in the case of short-term water level surges. For the study of transient seepage fields, the dangerous water level at which the dike is about to be destroyed can be calculated. At the same time, the choice of the best relief wells also provides an excellent reference value for the difficult-to-test wells in practical engineering. Based on the transient seepage field, the influence of various design schemes of relief wells on the phreatic line and seepage flow rate is studied, and the optimal seepage control scheme of relief wells under the transient seepage field is obtained.

\section{Governing Equation}

According to Darcy's law, the seepage equation of porous media can be expressed as follows [23]:

$$
Q=K A j=-K A \frac{\partial h}{\partial l}, V=K j,
$$

where $Q$ is seepage quantity; $K$ is hydraulic conductivity; $A$ is seepage cross-sectional area; $j$ is gradient; $h$ is hydraulic head; $l$ is head loss; and $V$ is the average flow velocity of the seepage model.

The differential formula of Darcy's law is as follows:

$$
V=-\frac{K}{\mu}\left(\frac{\partial p}{\partial z}+\rho g\right),
$$

where $\mu$ is viscosity; $K$ is permeability; $P$ is pressure; $\rho$ is density; and $G$ is acceleration of gravity.

According to the law of conservation of mass, it is generally believed that the mass of the fluid does not increase or decrease when it moves in the seepage field. It is assumed that there is fluid inflow in all directions of the unit body. The inflow rate is assumed to be $V_{x}, V_{y}$, and $V_{y}$, respectively, and the side lengths are expressed by $\mathrm{d} x, \mathrm{~d} y$, and $\mathrm{d} z$, respectively, as shown in Figure 1. 


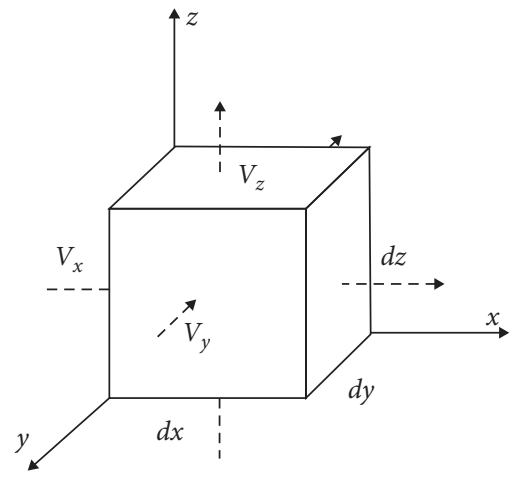

FIgURE 1: Velocity vector diagram and flow diagram of seepage unit.

The total seepage quantity in the cell can be calculated by superposition of the seepage quantity in $x, y$, and $z$ directions:

$$
-\left(\frac{\partial \rho V_{x}}{\partial x}+\frac{\partial \rho V_{y}}{\partial y}+\frac{\partial \rho V_{z}}{\partial z}\right) \mathrm{d} x \mathrm{~d} y \mathrm{~d} z=-\rho\left(\frac{\partial V_{x}}{\partial x}+\frac{\partial V_{y}}{\partial y}+\frac{\partial V_{z}}{\partial z}\right) \mathrm{d} x \mathrm{~d} y \mathrm{~d} z .
$$

The change rate of a point with mass $M$ in the cell can be expressed as follows:

$$
\frac{\partial M}{\partial \mathrm{t}}=\frac{\partial(n \rho \mathrm{d} x \mathrm{~d} y \mathrm{~d} z)}{\partial \mathrm{t}}=\frac{\partial(n \rho V)}{\partial \mathrm{t}},
$$

where $n$ is the porosity of soil; $\rho$ is the density of water; and $V$ is the volume of unit.

According to the law of conservation of mass, formula (3) is simplified, and the following formula can be obtained:

$$
-\left(\frac{\partial V_{x}}{\partial x}+\frac{\partial V_{y}}{\partial y}+\frac{\partial V_{z}}{\partial z}\right)=\rho g(\propto+n \beta) \frac{\partial H}{\partial t} .
$$

Equation (5) is the compressible seepage continuity equation of saturated soil. Since the compression modulus of soil and water is 0 , formula (5) can be changed into

$$
\frac{\partial V_{x}}{\partial x}+\frac{\partial V_{y}}{\partial y}+\frac{\partial V_{z}}{\partial z}=0
$$

Equation (6) is the continuity equation when the incompressible fluid moves in the rigid structure medium.

Richard extended Darcy's law to unsaturated seepage in 1931 and obtained the fundamental differential equation of unsaturated seepage :

$$
\frac{\partial}{\partial x}\left(k_{x} \frac{\partial h}{\partial x}\right)+\frac{\partial}{\partial y}\left(k_{y} \frac{\partial h}{\partial y}\right)+\frac{\partial}{\partial z}\left(k_{z} \frac{\partial h}{\partial z}\right)+q=\frac{\partial w}{\partial t},
$$

where $k_{x}, k_{y}, k_{z}$ is hydraulic conductivity along three directions, $q$ is boundary flow of the element body, $w$ is unit volume water content, and $t$ is time.

When the hydraulic conductivity in the $x, y$, and $z$ directions remains unchanged, and the unit is not subject to external rainfall and evaporation, there is no external inflow and outflow. We know

$$
k_{x} \frac{\partial^{2} h}{\partial x^{2}}+k_{y} \frac{\partial^{2} h}{\partial y^{2}}+k_{z} \frac{\partial^{2} h}{\partial z^{2}}=0 .
$$

If the permeability coefficient is isotropic and equal, equation (8) will become the Laplace operator:

$$
\frac{\partial^{2} h}{\partial x^{2}}+\frac{\partial^{2} h}{\partial y^{2}}+\frac{\partial^{2} h}{\partial z^{2}}=0 .
$$

Combining the continuity equation with Darcy' law results in Poisson's equation:

$$
k_{x} \frac{\partial^{2} h}{\partial x^{2}}+k_{y} \frac{\partial^{2} h}{\partial y^{2}}=q .
$$

Although equations (8) and (10) are for stable seepage differential equation, it can still be used when the fluid is incompressible and in unstable flow. (5),

When the fluid is in turbulence, according to formula

$$
\frac{\partial}{\partial \mathrm{x}}\left(k_{x} \frac{\partial h}{\partial x}\right)+\frac{\partial}{\partial y}\left(k_{y} \frac{\partial h}{\partial y}\right)+\frac{\partial}{\partial z}\left(k_{z} \frac{\partial h}{\partial z}\right)=-\rho g(\propto+n \beta) \frac{\partial h}{\partial t}=S_{s} \frac{\partial h}{\partial t},
$$

where $S_{\mathrm{s}}$ is the unit storage capacity $(1 / L)$.

When the permeability coefficient is assumed to be isotropic, formula (11) can be changed to

$$
\frac{\partial^{2} h}{\partial x^{2}}+\frac{\partial^{2} h}{\partial y^{2}}+\frac{\partial^{2} h}{\partial z^{2}}=\frac{S_{s}}{k} \frac{\partial h}{\partial t}
$$

The gradient of homogeneous soil on permeable foundation can be calculated by the following formula. 
Along the exudate,

$$
J=\frac{1}{\sqrt{1+m^{2}}}\left(\frac{h}{y}\right)^{0.5},
$$

where $m$ is the slope rate; $h$ is the height of fluid escape point; and $y$ is the fluid flow distance.

\section{Numerical Modelling}

3.1. Physical Conditions. This paper takes the Beijiang Dike as the research object and analyses the seepage field of the dike and the optimization of the antiseepage scheme of the relief well. The Beijiang Dike in Guangdong Province is located on the left bank of the lower reaches of the Beijiang River, with a total length of $63.346 \mathrm{~km}$. It is a flood control barrier for Guangzhou and the Pearl River Delta. It belongs to the first-class levee of the China and is one of the seven levees guaranteed by the whole country. More than $90 \%$ of piping effect of Beijiang Dike is caused by seepage of embankment foundation. Flood hazards are mainly concentrated in the area of the pile number $7+000-10+980$. In case of large floods, there are many dangers such as piping and sand bursting in pits, lowlands, ditches, and wells behind dikes. Some of them are very serious and need to be vigorously rescued to survive the floods. Therefore, seepage analysis is needed to solve related problems.

The seepage finite element analysis (FEA) method is used to model and analyze the $8+230$ section of the Shijiao segment of Beijiang Dike. The height of the dike section is $17.85 \mathrm{~m}$, the total length of the section is $181 \mathrm{~m}$, the width of the top of the dike is $8.0 \mathrm{~m}$, the ratio of the upstream batter is $1: 3$, the ratio of the downstream slope above the original road surface is $1: 3$, and the ratio of the downstream slope below the original road surface is $1: 38$. The Shijiao segment is built on a robust permeable layer about $15 \sim 25 \mathrm{~m}$ thick. The cross section of the embankment is approximately trapezoidal, and the materials of the embankment body include silt, clay, silty clay, and artificial fill.

The upper layer of dike foundation is clay, and the lower is a strong permeable layer, which mainly includes fine sand layer, medium-coarse sand layer, and gravel layer. Assuming that the permeability of soil in the same region is uniform, it is an isotropic medium [24-26], the geological parameters are shown in Table 1, and the model schematic diagram is shown in Figure 2.

3.2. Verification of Grid Independence. For numerical simulation, it is necessary to determine the independence between the number of meshes used in the calculation and the results obtained, that is, to verify the grid independence. The outer river level is 11.38 meters, and the global element size of the grid is set to $0.7 \mathrm{~m}, 1 \mathrm{~m}$, and $1.3 \mathrm{~m}$. The measured value of the water head is provided by the Beijiang Dike administration department.

From Table 2, it is not difficult to find that three different grid values almost coincide with each other. It can be concluded that the grids with $1 \mathrm{~m}$ element size are grid- independent, so we can choose the grids with $1 \mathrm{~m}$ element size for numerical simulation.

3.3. Validation of Effectiveness. The validation of the model is mainly based on the comparison between the numerical simulation of the water head of the phreatic line and the actually measured water head of the piezometric pipe under four working conditions. It is known that three pressure measuring pipes are located at horizontal distances of $48 \mathrm{~m}$, $134 \mathrm{~m}$, and $181 \mathrm{~m}$ under the conditions of water level of $8.7 \mathrm{~m}, 9.54 \mathrm{~m}, 10.56 \mathrm{~m}$, and $11.38 \mathrm{~m}$ in the outer river. The measured values of water head are shown in Table 3.

The boundary conditions of numerical simulation are as follows: the upstream water level is in the outer river, and the downstream water level is in the measured value of a B3 piezometer. The simulation results are shown in Figure 2.

After obtaining the specific numerical simulation data, we compare the numerical simulation data with the actual value of the pressure tube and show it in the form of a graph. Figure 3 shows the numerical simulation head value under the condition of $8.7 \mathrm{~m}, 9.54 \mathrm{~m}, 10.56 \mathrm{~m}$, and $11.38 \mathrm{~m}$ of the outer river and the actual measured head value of the piezometer tube.

Through the analysis and comparison of Figure 4, we can see that the theoretical value of pressure measurement management simulated by the model is very close to the actual measurement value. The maximum error value is not more than $0.32 \mathrm{~m}$. Meanwhile, the minimum error is 0 and the average error value is $0.104 \mathrm{~m}$. Generally speaking, the simulation value is larger than the measured value, and the simulation results are more conservative and safe. The comprehensive results show that the established numerical simulation model is very close to the actual situation.

\section{Numerical Results and Discussion}

In this section, the transient state of Shijiao segment is simulated numerically. Then, the antiseepage measures and optimization of the use of the relief well are proposed for the dike. Through numerical simulation, we can analyze various embankment conditions including steady state, transient state, and antiseepage measures with relief wells, including phreatic line, seepage quantity, and gradient. The boundary conditions of the outer river level (upstream water level) are set in Table 4.

4.1. Transient Seepage Analysis. The most probable cause of embankment failure in practical engineering is the seepage damage. Under the seepage action of the dike body and foundation, soil particles are lost and local damage is deformed (such as piping or flowing soil) due to its mechanical or chemical action. The seepage of water will increase the phreatic of soil and decrease the suction of the matrix in the unsaturated area, thus increasing the possibility of slope instability. Especially, when the water level changes, the sudden rise and fall of the water level in the dam body will make the seepage stress in the soil body larger, which is easier to destroy the slope soil body. Therefore, the transient 
TABLE 1: Model hydraulic conductivity table.

\begin{tabular}{llccc}
\hline Material & Dam body & Fine sand layer & Medium-coarse sand layer & Gravel layer \\
\hline Hydraulic conductivity K $(\mathrm{cm} / \mathrm{s})$ & $1.94 \times 10^{-4}$ & $5.7 \times 10^{-2}$ & $2.2 \times 10^{-1}$ & $1.3 \times 10^{-1}$ \\
\hline
\end{tabular}

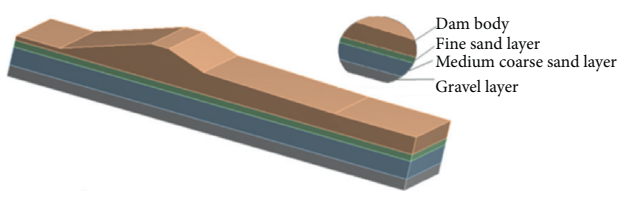

(a)

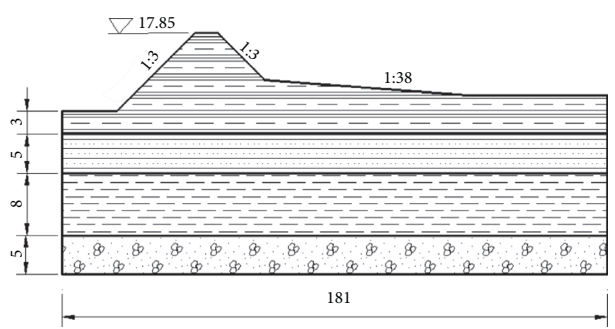

(b)

Figure 2: Schematic diagram of the embankment (unit: m). (a) Three-dimensional dike. (b) Typical section diagram of Shijiao segment.

TABLE 2: Grid independence validation (unit: $\mathrm{m}$ ).

\begin{tabular}{lcccc}
\hline Pressure tube head & $0.7 \mathrm{~m}$ grid & $1 \mathrm{~m}$ grid & $1.3 \mathrm{~m}$ grid & Measured value \\
\hline B0 & 11.38 & 11.38 & 11.38 & 11.38 \\
B1 & 10.86 & 10.82 & 10.88 & 10.71 \\
B2 & 10.24 & 10.2 & 10.18 & 10.17 \\
B3 & 9.76 & 9.74 & 9.75 & 9.76 \\
\hline
\end{tabular}

TABLE 3: Measured water level of the $8+232$ piezometric pipe (unit: $\mathrm{m}$ ).

\begin{tabular}{lcccc}
\hline Manometer number & 8.7 outer river level & 9.54 outer river level & 11.38 outer river level & 10.56 outer river level \\
\hline B1 & 8.69 & 9.02 & 10.71 & 9.92 \\
B2 & 8.53 & 8.99 & 10.17 & 9.76 \\
B3 & 8.36 & 9.02 & 9.76 & 9.32 \\
\hline
\end{tabular}

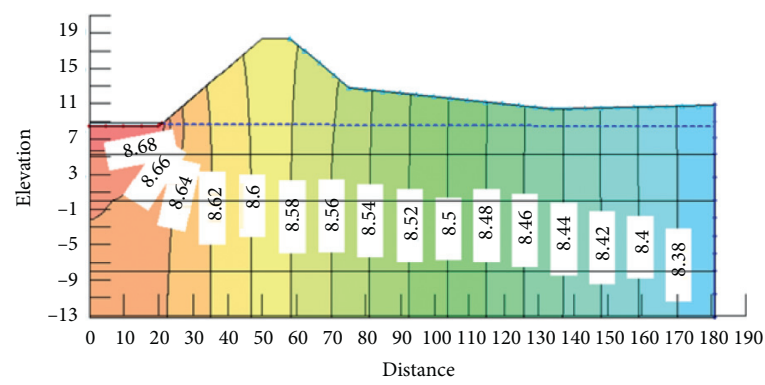

(a)

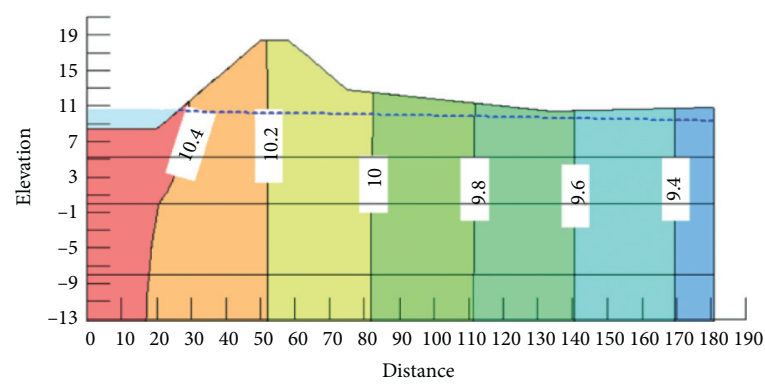

(c)

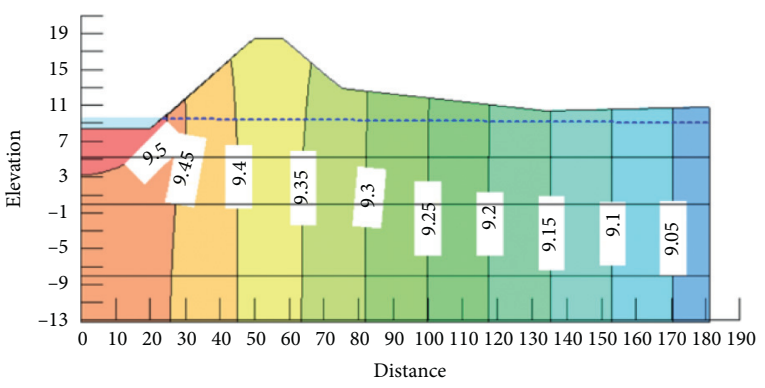

(b)

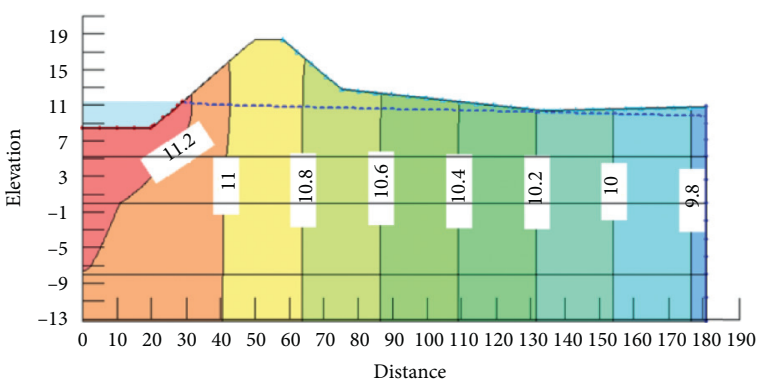

(d)

FIGURE 3: Numerical simulation results where the outer river water level is (a) $8.7 \mathrm{~m}$, (b) $9.54 \mathrm{~m}$, (c) $10.56 \mathrm{~m}$, and (d) $11.38 \mathrm{~m}$. 


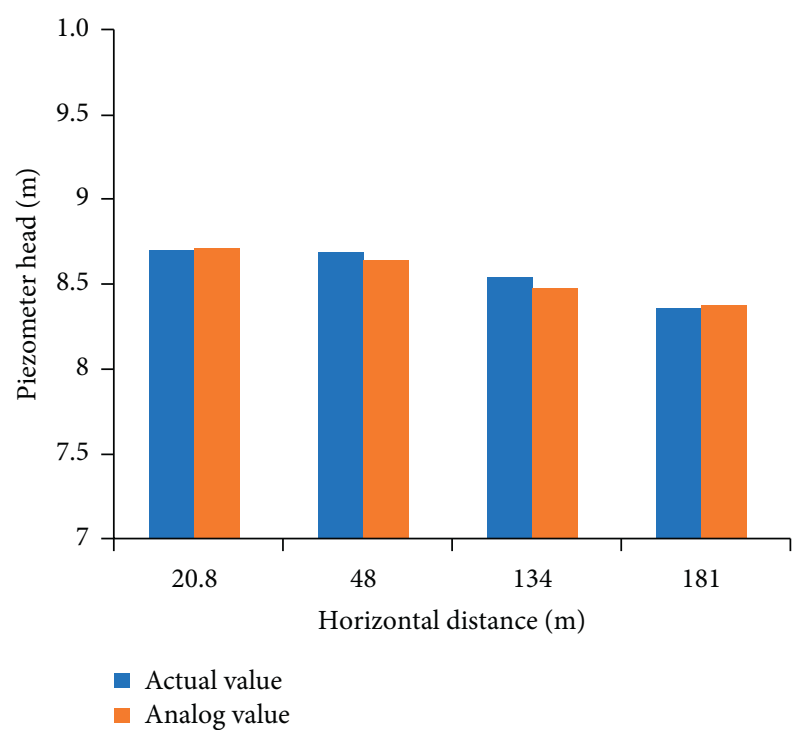

(a)

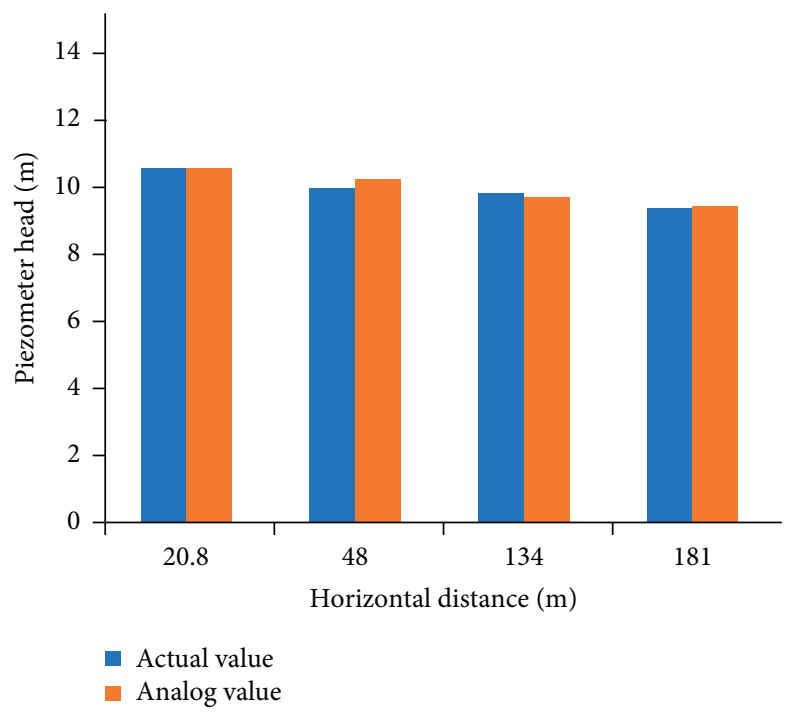

(c)

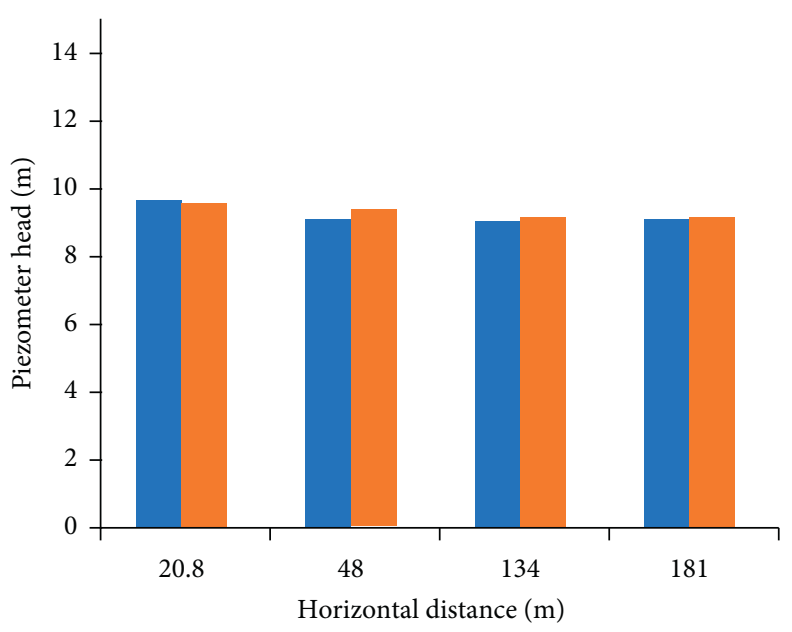

- Actual value

- Analog value

(b)

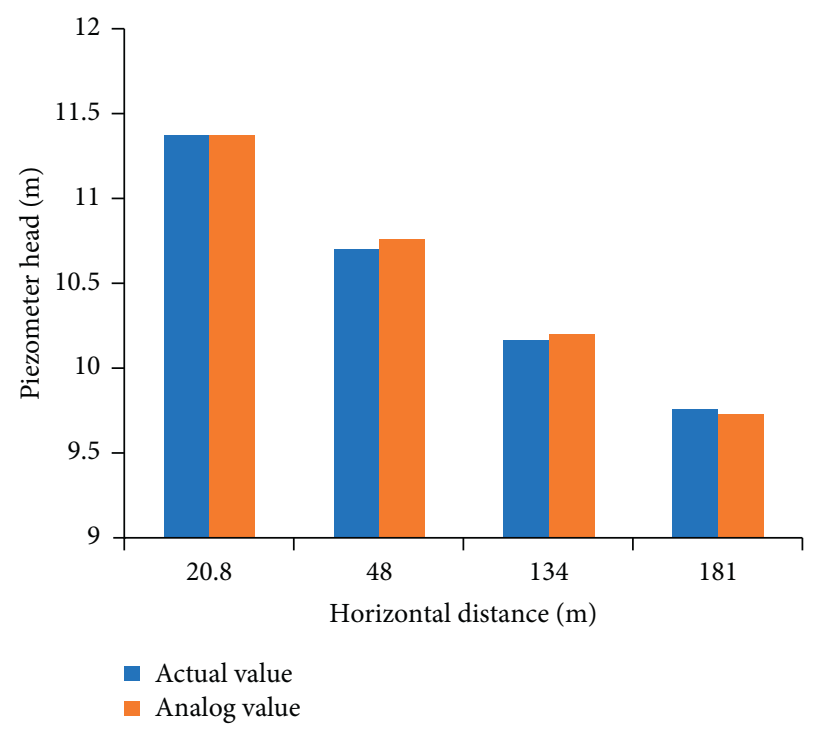

(d)

FIGURe 4: Comparison between calculated head value and measured head value where the outer river water level is (a) $8.7 \mathrm{~m},(\mathrm{~b}) 9.54 \mathrm{~m}$, (c) $10.56 \mathrm{~m}$, and (d) $11.38 \mathrm{~m}$.

TABLE 4: Boundary conditions of the transient upstream water level.

\begin{tabular}{lc}
\hline Time (hour) & Outer river level (meter) \\
\hline 0 & 9.5 \\
6 & 10 \\
12 & 10.5 \\
18 & 11.5 \\
24 & 12.5 \\
30 & 13.5 \\
36 & 14 \\
42 & 14.5 \\
48 & 15 \\
60 & 16 \\
72 & 17 \\
\hline
\end{tabular}

analysis of the embankment can better predict the water level when the embankment is damaged, which has a strong guiding significance for the safe operation of the embankment. In Figure 5, elevation and distance units are meters.

From Figure 5, it can be concluded that as the water level increases, the change of phreatic line becomes larger and larger, equipotential line value of dam section increases, and the lowest equipotential line value reaches 11 at the highest water level. When the outer river level is about 15 meters, the phreatic line crosses the foot of the backwater slope above the original road surface. With the increase of rainfall, piping and flowing soil will easily occur here.

From Figure 6(a) seepage quantity variation chart, it can be seen that the transient seepage quantity is larger than the 


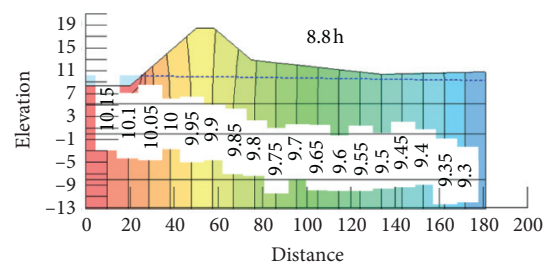

(a)

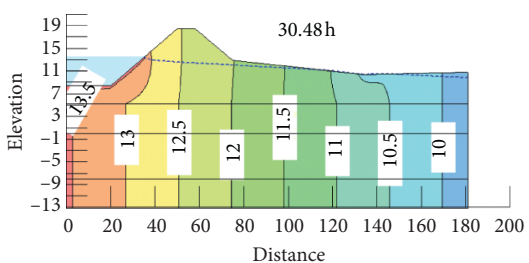

(d)

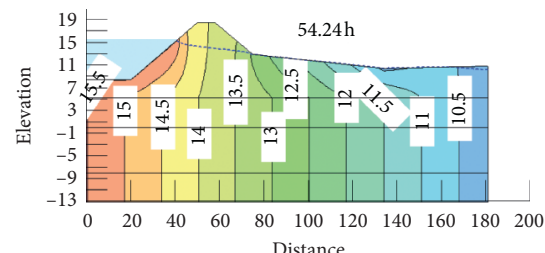

(g)

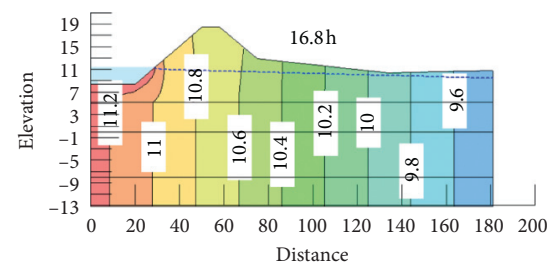

(b)

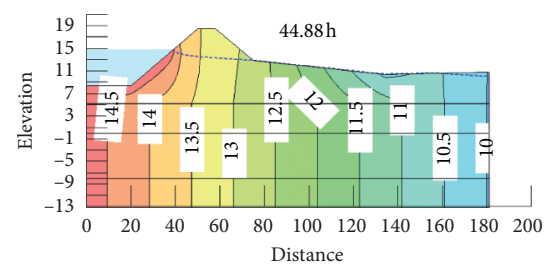

(e)

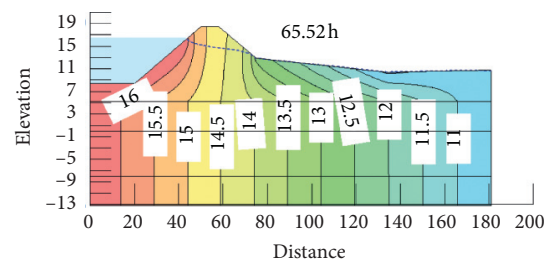

(h)

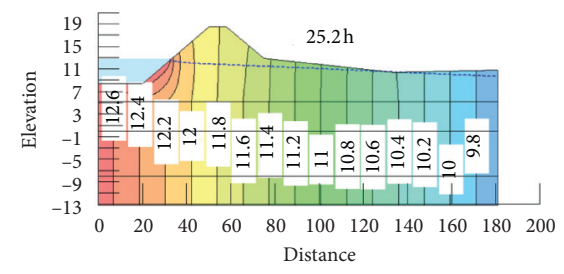

(c)

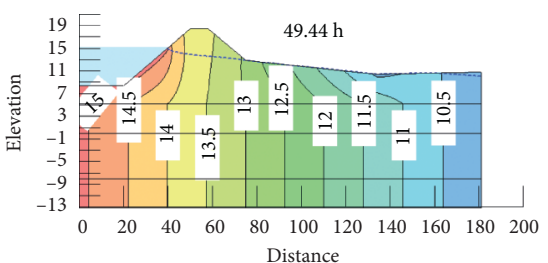

(f)

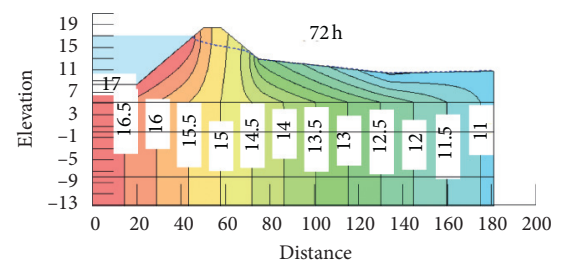

(i)

Figure 5: Transient numerical simulation of phreatic line variation.

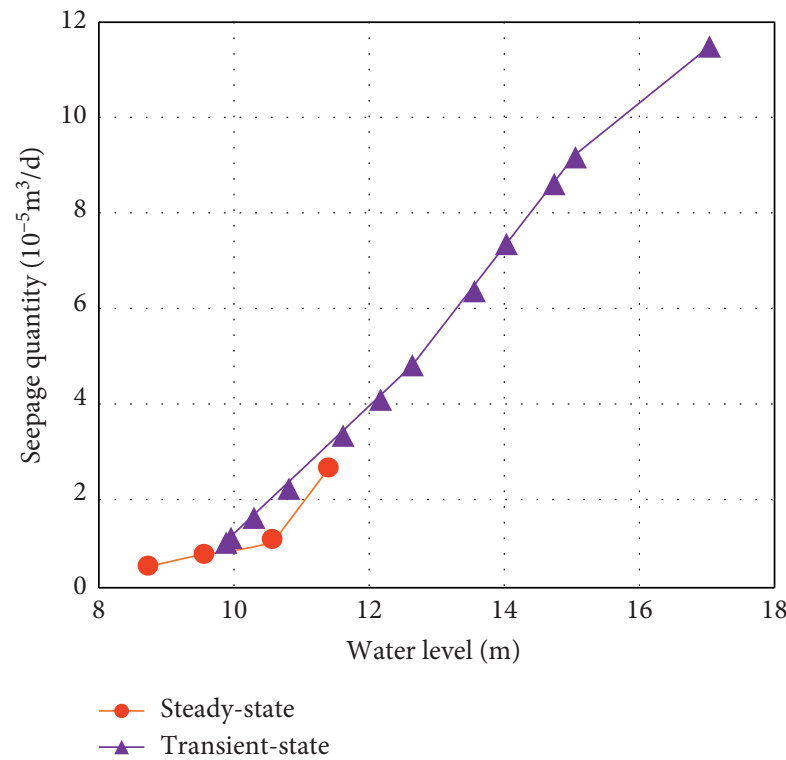

(a)

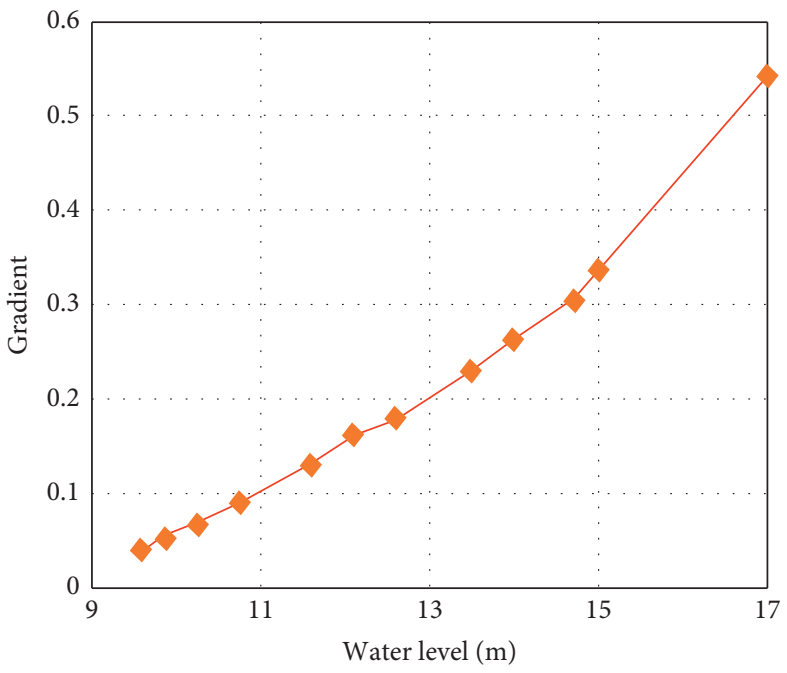

(b)

Figure 6: (a) Changes in transient and steady-state seepage quantity. (b) Changes in transient gradient.

steady seepage flow under the same water level, and the maximum seepage quantity reaches $9.43 \times 10^{-5} \mathrm{~m}^{3} / \mathrm{d}$. Higher safety measures should be taken when the same water level falls in the rain. With the increase of the water level, the seepage of the dam body increases gradually, and the gradient of dam body increases in a curve. When the water level is $15.78 \mathrm{~m}$, the gradient reaches 0.5 [27] and the embankment is damaged. In order to increase the safety of the embankment, we add the antiseepage measures of relief wells to the embankment.

4.2. Seepage Analysis of Relief Wells. As one of the primary seepage control means, relief wells are widely used in dike 


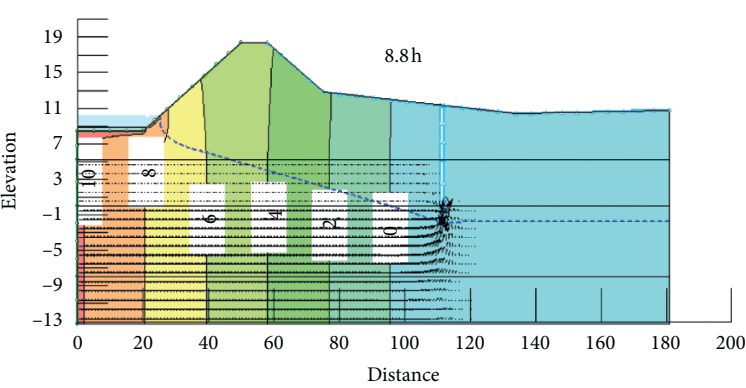

(a)

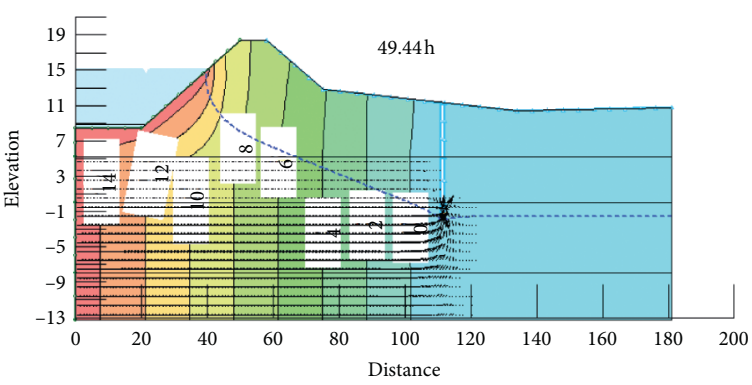

(c)

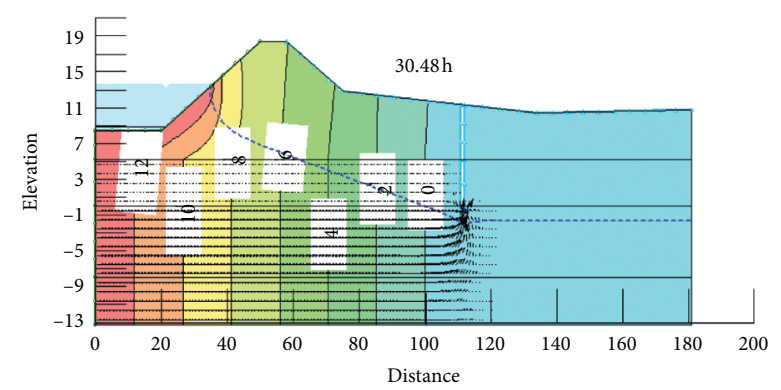

(b)

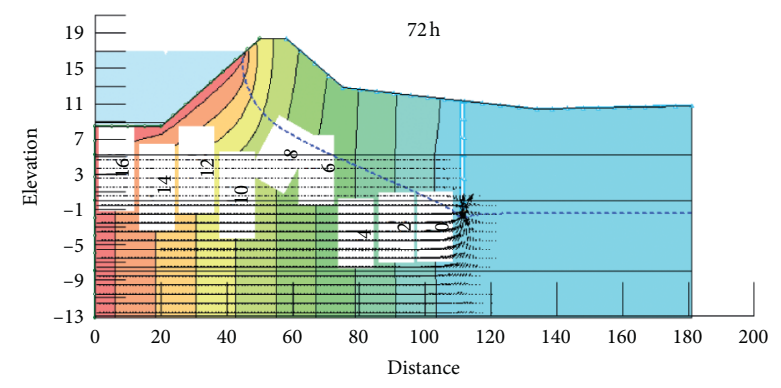

(d)

FIGURE 7: Variation diagram of the phreatic line in numerical simulation of relief wells.

engineering. Relief wells are often used in dikes and dams. If the design and construction are unreasonable or the operation and management are not good, the output of water will be small, the effect of decompression will be poor, and the safety of dikes will be endangered. Therefore, it is of considerable significance to study the location and penetration depth of relief wells.

We analyzed the relief well depths of $10 \mathrm{~m}, 11 \mathrm{~m}, 12.5 \mathrm{~m}$, and $16.5 \mathrm{~m}$ and analyzed the relief wells with a penetration depth of $12.5 \mathrm{~m}$ at horizontal distances of $84 \mathrm{~m}, 94 \mathrm{~m}$, and $114 \mathrm{~m}$.

The higher the water level of the outer river, the higher the height of the phreatic line and the greater the risk of breaking dikes. As shown in Figure 7, the relief well goes deep into the strong permeable layer. It can be seen that the height of the phreatic line of the relief well decreases obviously after the relief well has passed (the lowering elevation is between $8 \mathrm{~m}$ and $12 \mathrm{~m}$ ) as shown in Figure 8, and a large amount of water is discharged from the relief well to prevent piping, flowing soil, swamping, and other phenomena. The equipotential line value on the left side of the relief well has almost changed to 0 , which shows that the relief well plays a significant role.

As shown in Figure 9(a), the effect of drainage and decompression of relief wells is greatly affected by penetration depth, which gradually increases with the increase of penetration depth. When penetration depth increases from $9 \mathrm{~m}$ to $11 \mathrm{~m}$, the effect of drainage and decompression is relatively small. As shown in Figure 9(a), the seepage quantity of the four relief wells increases with the increase of the water level. It can be seen that the depth of the relief wells

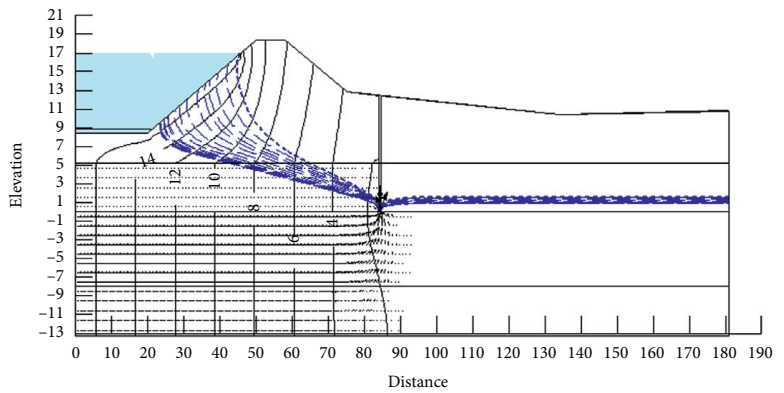

FIGURE 8: Variation diagram of phreatic line in numerical simulation of relief wells.

is $16.5 \mathrm{~m}$, which has the best seepage control effect on the embankment. The optimal seepage quantity is $4.51 \times 10^{-10} \mathrm{~m}^{3} / \mathrm{d}$, which is remarkable when the seepage quantity is $10^{-5} \mathrm{~m}^{3} / \mathrm{d}$ compared with that without the relief wells. It can be seen that if comprehensive factors such as economy and technology are not considered, the deeper the penetration depth of relief wells in different permeability coefficients, the better.

In Figure 9(b), we place the relief wells with a depth of $12.5 \mathrm{~m}$ at horizontal distances of $84 \mathrm{~m}, 95 \mathrm{~m}$, and $114 \mathrm{~m}$. The seepage quantity varies from one well to another, with a difference of nearly 10 times. It can be seen that due to the different geological conditions, the same relief wells in different locations have a vast difference in effect. It can be seen from the figure that the seepage control effect is the best when the horizontal distance is $95 \mathrm{~m}$, and the minimum seepage quantity is $2.37 \times 10^{-10} \mathrm{~m}^{3} / \mathrm{d}$. 


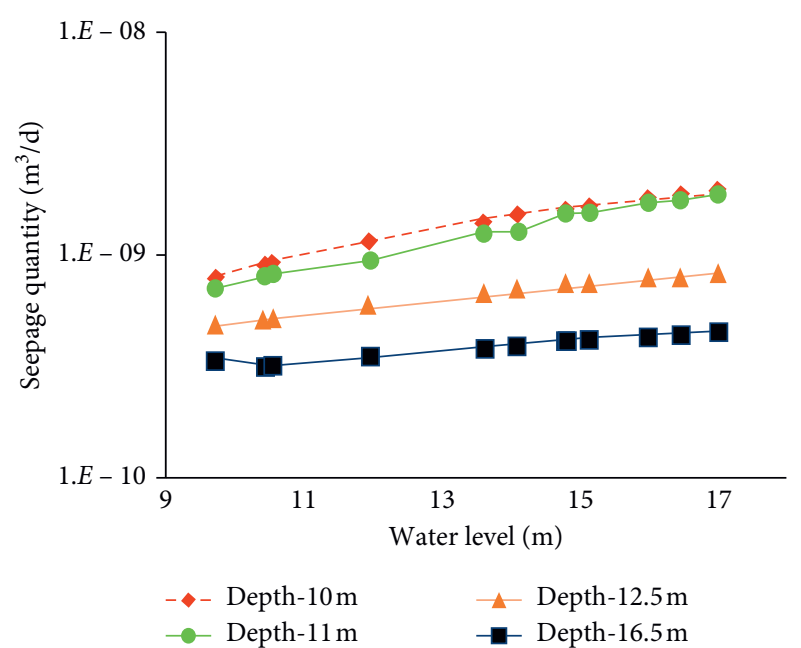

(a)

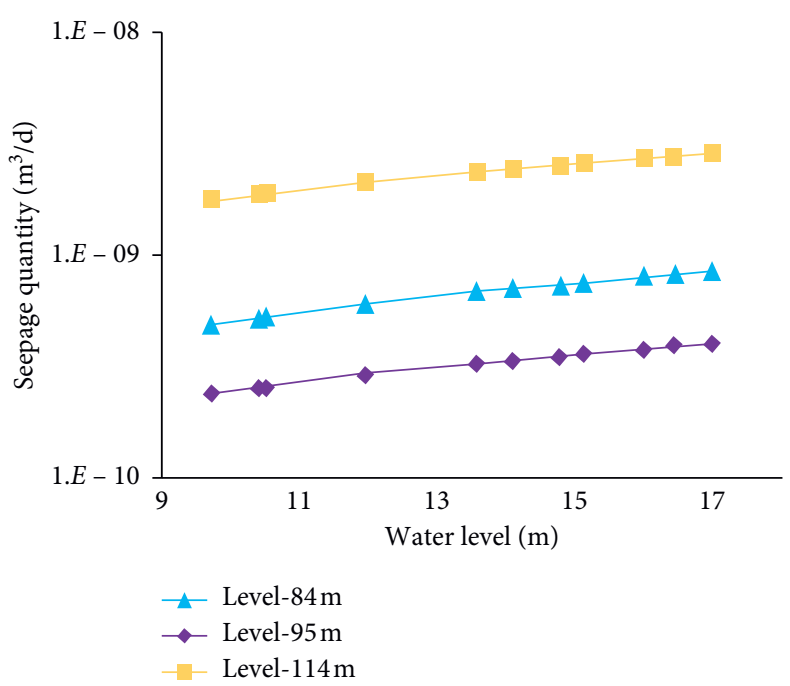

(b)

FIGURE 9: Seepage quantity of added relief wells. (a) Seepage quantity of relief wells with different depths. (b) Seepage quantity of relief wells with different positions.

\section{Conclusions}

The geological variation of embankment foundation is great, the terrain is complex, and a lot of data are difficult to observe. This paper calculates the transient seepage field of the embankment by numerical simulation and chooses appropriate antiseepage measures of relief wells. Finally, different antiseepage schemes are analyzed.

(1) The average error value of model validation is $0.104 \mathrm{~m}$, which is close to the actual situation. We can accurately and effectively simulate the seepage field and get the gradient, the phreatic line, and the seepage velocity. When the water level is $15.78 \mathrm{~m}$, the gradient reaches 0.5 and the embankment is damaged. Accurate numerical simulation can provide sufficient support for the safety evaluation of embankment seepage.

(2) As a seepage control measure, the effect of relief wells is significantly different from that of non-pressurerelief wells. The minimum seepage quantity after relief wells is $8.4 \times 10^{-10} \mathrm{~m}^{3} / \mathrm{d}$ and without a relief well is $1.65 \times 10^{-5} \mathrm{~m}^{3} / \mathrm{d}$. The lowering of the water head of the phreatic line is up to $12 \mathrm{~m}$, and the lowering of seepage quantity is beneficial to prevent piping, flowing soil, swamping, and other phenomena in the embankment, which plays an indispensable role in the safety of the embankment.

(3) At the same water level, the transient seepage quantity is larger than the steady seepage quantity. Therefore, the safety hazards of dikes are greater when rapid rainfall occurs, and safer antiseepage measures should be taken.

\section{Data Availability}

The raw/processed data required to reproduce these findings cannot be shared at this time as the data also form part of an ongoing study.

\section{Conflicts of Interest}

The authors declare that they have no conflicts of interest.

\section{Authors' Contributions}

Wenbing $\mathrm{Xu}$, Chuan $\mathrm{Xu}$, and Qinghe Yao contributed equally to this work.

\section{Acknowledgments}

This work was partly supported by the National Key R\&D Program for HPC under grant no. 2016YFB0200603 and the National Key R\&D Program for International Cooperation, grant no. 2018YFE9103900. The Guangdong MEPP Fund (no. GDOE[2019] A01), the project of the Guangzhou Science and Technology Program, grant no. 201704030089, and the NSFC project (grant no. 11972384) also supported this research.

\section{References}

[1] X. F. Guo, D. Dias, and Q. J. Pan, "Probabilistic stability analysis of an embankment dam considering soil spatial variability," Computers and Geotechnics, vol. 113, pp. 093-103, 2019.

[2] A. Kacimov and Y. Obnosov, "Analytical solutions for seepage near material boundaries in dam cores: the davison-kalinin problems revisited," Applied Mathematical Modelling, vol. 36, no. 3, pp. 1286-1301, 2012.

[3] T. Jiang, J. Zhang, W. Wan, S. Cui, and D. Deng, "3D transient numerical flow simulation of groundwater bypass seepage at the dam site of Dongzhuang hydro-junction," Engineering Geology, vol. 231, pp. 176-189, 2017.

[4] W. J. Hu, Test and Numerical Simulation Study on Seepage Control Effect of Embankment Foundation Engineering with Weak Permeable Layer, Tianjin University, Tianjin, China, 2017. 
[5] G. Gottardi, C. G. Gragnano, I. Rocchi, and M. Bittelli, "Assessing river embankment stability under transient seepage conditions," Procedia Engineering, vol. 158, pp. 350$355,2016$.

[6] P. Khanh and L. Hyobum, "Influence of hydraulic characteristics on stability of unsaturated slope under transient seepage conditions," Landslides, vol. 15, no. 9, pp. 1787-1799, 2018.

[7] S. Li, J. Wang, L. Li, S. Shi, and Z. Zhou, "The theoretical and numerical analysis of water inrush through filling structures," Mathematics and Computers in Simulation, vol. 162, pp. 115-134, 2019.

[8] L. Yao, S. Feng, X. Mao, Z. Huo, S. Kang, and D. A. Barry, "Coupled effects of canal lining and multi-layered soil structure on canal seepage and soil water dynamics," Journal of Hydrology, vol. 430-431, pp. 91-102, 2012.

[9] S. P. Neuman, "Theoretical derivation of darcy's law," Acta Mechanica, vol. 25, no. 3-4, pp. 153-170, 1977.

[10] L. A. Richards, "Capillary conduction of liquids through porous mediums," Physics, vol. 1, no. 5, pp. 318-333, 1931.

[11] L. Lam, D. G. Fredlund, and S. L. Barbour, "Transient seepage model for saturated-unsaturated soil systems: a geotechnical engineering approach," Canadian Geotechnical Journal, vol. 24, no. 4, pp. 565-580, 1987.

[12] Y. Qing, H. Z. Li, J. H. Jing et al., "Experimental studies on seepage failure of the top stratum at a weak spot in doublelayer dike foundations," Advanced Materials Research, vol. 368-373, pp. 2387-2393, 2012.

[13] F. Armin, S. Farzin, and M. Behnam, "Optimum size for clay core of alavian earth dam by numerical simulation," Iranica Journal of Energy \& Environment, vol. 5, no. 3, pp. 240-246, 2014.

[14] F. R. Salazar, M. Á. Toledo, and E. Oñate, "Data-based models for the prediction of dam behaviour: a review and some methodological considerations," Archives of Computational Methods in Engineering, vol. 24, no. 1, pp. 1-21, 2017.

[15] M. C. Morán, Analysis of Seepage and Dam Slope Stability of Dam Body of Fosi Reservoir, Taiyuan University of Technology, Taiyuan, China, 2014.

[16] J. F. Zhang, G. S. Zhu, and G. L. Cao, "Numerical simulation study on the diffusion deformation expansion process and the control function of suspended cutoff wall," Journal of Yangtze River Scientific Research Institute, vol. 21, no. 6, pp. 47-50, 2004.

[17] A. Mocllmann, P. A. Vermeer, and M. Huber, "A probabilistic finite element analysis of embankment stability under transient seepage conditions," Georisk: Assessment and Management of Risk for Engineered Systems and Geohazards, vol. 5, no. 2, pp. 110-119, 2011.

[18] M. Huber, A. Moellmann, and P. A. Vermeer, "PC-Riverreliability analysis of embankment stability," Georisk: Assessment and Management of Risk for Engineered Systems and Geohazards, vol. 5, no. 2, pp. 132-142, 2011.

[19] L. Z. Wu, L. M. Zhang, Y. Zhou et al., "Analysis of multi-phase coupled seepage and stability in anisotropic slopes under rainfall condition," Environmental Earth Sciences, vol. 76, no. 14, p. 469, 2017.

[20] K. H. Qiu, D. W. Lu, and B. Huang, "Numerical analysis of seepage stability of embankment engineering," Yangtze River, vol. 42, no. s2, pp. 155-156, 2011.

[21] T. Zhang, "Analysis on the effect of anti-seepage engineering of shijiao segment in beijiang dike," Chinese Journal of Rock Mechanics and Engineering, vol. 28, no. 11, pp. 2235-2241, 2009.
[22] J. J. Li, "Numerical analysis of influencing factors of the operation effect of the relief well," Journal of Yangtze River Scientific Research Institute, vol. 33, no. 5, pp. 151-154, 2016.

[23] S. Whitaker, "Flow in porous media I: a theoretical derivation of darcy's law," Transport in Porous Media, vol. 1, no. 1, pp. 3-25, 1986.

[24] Z. Y. Ai, Y. F. Chen, and X. B. Jiang, "Behavior of laterally and vertically loaded piles in multi-layered transversely isotropic soils," Applied Mathematical Modelling, vol. 51, pp. 561-573, 2017.

[25] Y. C. Cheng and Z. Y. Ai, "Consolidation analysis of transversely isotropic layered saturated soils in the Cartesian coordinate system by extended precise integration method," Applied Mathematical Modelling, vol. 40, no. 4, pp. 26922704, 2016.

[26] R. T. Yan, X. Y. Zhao, M. B. Yu et al., "Isotropic compression characteristics of clayey soil saturated bysalty solution," Rock \& Soil Mechanics, vol. 39, no. 1, pp. 129-138, 2018.

[27] J. Q. Zhao, "Stability analysis of embankment seepage in aihe treatment project based on hydraulics method," Shaanxi Water Resources, vol. 2, pp. 134-135, 2017. 